\title{
Blast-Resistant Improvement of Sandwich Armor Structure with Aluminum Foam Composite
}

\author{
Shu Yang and Chang Qi \\ School of Automotive Engineering, State Key Laboratory of Structural Analysis for Industrial Equipment, \\ Dalian University of Technology, Dalian 116024, China \\ Correspondence should be addressed to Chang Qi; qichang@dlut.edu.cn
}

Received 30 May 2013; Accepted 26 August 2013

Academic Editor: Bin Zhang

Copyright (C) 2013 S. Yang and C. Qi. This is an open access article distributed under the Creative Commons Attribution License, which permits unrestricted use, distribution, and reproduction in any medium, provided the original work is properly cited.

Sandwich armor structures with aluminum foam can be utilized to protect a military vehicle from harmful blast load such as a landmine explosion. In this paper, a system-level dynamic finite element model is developed to simulate the blast event and to evaluate the blast-resistant performance of the sandwich armor structure. It is found that a sandwich armor structure with only aluminum foam is capable of mitigating crew injuries under a moderate blast load. However, a severe blast load causes force enhancement and results in much worse crew injury. An isolating layer between the aluminum foam and the vehicle floor is introduced to remediate this drawback. The results show that the blast-resistant capability of the innovative sandwich armor structure with the isolating layer increases remarkably.

\section{Introduction}

For ground vehicles, blast loads from landmine explosions and ballistic loads from a bullet or a missile produce much damage to the vehicle structure and result in severe injuries to crew members. Armor structures are usually employed to protect a military vehicle and crew from these extreme loads. Metal foam is an ideal choice of sacrificial material for blast protection due to its low density, a characteristic that is very preferable for lightweight applications. The porus nature of the foam helps in heat dissipation and also provides acoustic damping [1-3]. Besides all these benefits, an undesired phenomenon observed when using foam material for blast protection is that, under certain conditions, the peak force transmitted to the protected structure can be even higher than when the foam material is not used [4]. This unexpected phenomenon is called "force enhancement" and needs to be considered in vehicle armor design. As a result, application of foam material for blast protection design is still limited at the present time.

In this context, to evaluate the blast-resistant performances of the aluminum foam sandwich armor structure, as well as to explore design countermeasures against force enhancement, dynamic finite element models are presented in this paper for simulating the blast process and the dynamic responses of the sandwich armor, as well as the crew injuries. An isolating layer is introduced to the sandwich armor structure, which is demonstrated to be effective in mitigating the crew injury based on numerical simulation results.

\section{Modeling Description}

The blast process is both difficult and expensive to test. Moreover, testing of structural damage processes from the blast loads is no easy task either. Numerical techniques, such as the finite element method, are employed for blast process simulation as well as for structural damage analyses. In this study, the finite element models were developed for numerical simulations based on the LS-DYNA platform. Altair HYPERMESH and LS-PREPOST were utilized for preand post-processing, respectively.

2.1. Vehicle Model. Finite element (FE) model of a typical military wheeled vehicle has been developed previously, which is ready to be utilized in this research. The geometric information in the FE model was based on the CAD data of the vehicle obtained from the Internet. Properties of various materials, such as steel, rubber, and glass, in the model were 


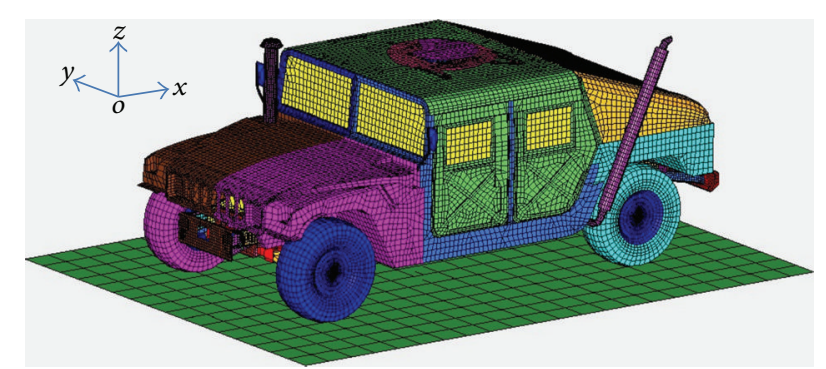

FIGURE 1: Finite element model of a military vehicle for blast protection design.

imported from other publicly available FE vehicle models. The FE model consists of 56851 elements with 60204 nodes.

2.2. Underbody Armor Model. In order to protect the crew members of a military vehicle at the time when dangerous loads, such as landmine blast load, are exerted on the vehicle body, it is essential to add an armor structure to the vehicle body. Underbody armor is a kind of protective structure mainly used against threats from the ground. The armor, which consists of a back aluminum panel and a layer of aluminum foam, is attached to the vehicle floor for enhanced blast-resistant capabilities of the vehicle.

The back facesheet of the two types of sandwich panel is made of aluminum alloy AA6061-T4 with mechanical properties: mass density $\rho=2700 \mathrm{~kg} / \mathrm{m}^{3}$, Young's modulus $E=$ $69 \mathrm{GPa}$, Poisson's ratio $v=0.28$, initial yield strength $\sigma_{y}=$ 110.3 MPa, and ultimate strength $\sigma_{u}=213 \mathrm{MPa}$. To take strain hardening effects into account, the energy equivalent plateau stress can be calculated as [5]

$$
\sigma=\sqrt{\frac{\sigma_{y} \sigma_{u}}{1+n}}
$$

where $n$ is the strain hardening exponent of the material, $n=0.2$, and the plateau stress for AA6061-T4 adopted here is $139.9 \mathrm{MPa}$. Figure 1 shows the typical engineering stress-strain curves for the aluminum alloy AA6061T4. The sheets are represented by material model 24 (*MAT_PIECEWISE_LINEAR_PLASTIC) provided by LSDYNA [6]. Since the aluminum is insensitive to the strain rate dependency, here the strain rate dependency is neglected [7]. [8]:

The yield criterion $\Gamma$ of aluminum foam is given as follows

$$
\Gamma=\widehat{\sigma}-\sigma_{y} \leq 0 .
$$

Here, $\sigma_{y}$ is the yield stress and $\widehat{\sigma}$ is the equivalent stress which is defined as

$$
\widehat{\sigma}^{2}=\frac{\sigma_{v}^{2}+\kappa^{2} \sigma_{m}^{2}}{1+(\kappa / 3)^{2}},
$$

where $\sigma_{v}$ is the von Mises effective stress defined as

$$
\sigma_{v}=\sqrt{\frac{3}{2} \sigma^{\mathrm{dev}}: \sigma^{\mathrm{dev}}}
$$

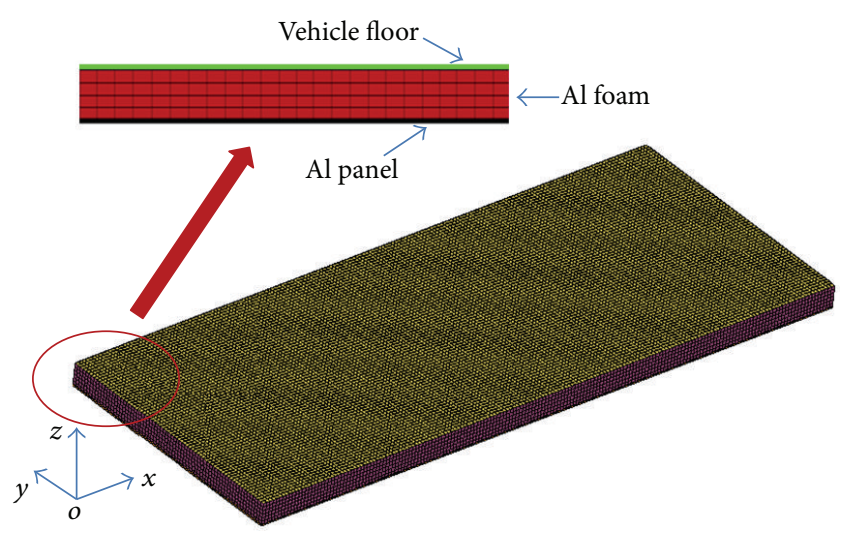

FIGURE 2: FE model of underbody armor plate for blast protection.

where $\sigma^{\text {dev }}$ is the deviatoric stress tensors and $\sigma_{m}$ is the hydrostatic stress tensors.

The yield stress $\sigma_{y}$ can be expressed with the plateau stress $\sigma_{p}$, the shape parameter of yield surface $\kappa$, the equivalent strain $\widehat{\varepsilon}$, the compaction strain $\varepsilon_{d}$, and the hardening parameters $\kappa_{2}, \gamma$, and $\beta$ :

$$
\begin{aligned}
\sigma_{y}=\sigma_{p}+\gamma \frac{\widehat{\varepsilon}}{\varepsilon_{d}} & +\kappa_{2} \ln \left(\frac{1}{1-\left(\widehat{\varepsilon} / \varepsilon_{d}\right)^{\beta}}\right), \\
\kappa^{2}= & \frac{9}{2} \frac{\left(1-2 v^{p}\right)}{\left(1+v^{p}\right)}, \\
0 & \leq \kappa^{2} \leq \frac{9}{2} .
\end{aligned}
$$

The equivalent and compaction strain $\widehat{\varepsilon}, \varepsilon_{d}$ is given as

$$
\begin{gathered}
\widehat{\varepsilon}^{2}=\left(1+\left(\frac{\kappa}{3}\right)^{2}\right)\left[\varepsilon_{e}^{2}+\frac{1}{\kappa^{2}} \varepsilon_{m}^{2}\right], \\
\varepsilon_{d}=-\frac{9+\kappa^{2}}{3 \kappa^{2}} \ln \left(\frac{\rho_{f}}{\rho_{f 0}}\right),
\end{gathered}
$$

where $\rho_{f}$ and $\rho_{f 0}$ and the density of aluminum foam and the density of the base material.

FE model of the underbody armor structure is shown in Figure 2. Both the aluminum panel and the aluminum foam are modeled by reduced one-point integration brick element. The nodes of different components are tied together along the material interface. The aluminum foam material [9] in use has the following material properties: $\rho_{f}=300 \mathrm{~kg} / \mathrm{cm}^{3}$, $E=1500 \mathrm{MPa}, v^{p}=0.05, \kappa=2.1, \gamma=6.10, \varepsilon_{d}=2.2$, $\kappa_{2}=38.1 \mathrm{MPa}, \beta=3.1, \sigma_{p}=4.41 \mathrm{MPa}$, and $\varepsilon_{\mathrm{cr}}=0.1$.

Material model MODIFIED_CRUSHABLE_FOAM of LS-DYNA was used to represent the material behavior of the aluminum foam. This model includes the strain rate effect of the foam material under high speed impact loads. The PIECEWISE_LINEAR_PLASTICITY card is used for modeling of both the front panel and the vehicle floor. Strain rate effect of aluminum is accounted by using the Cowper and Symonds model [10]. 


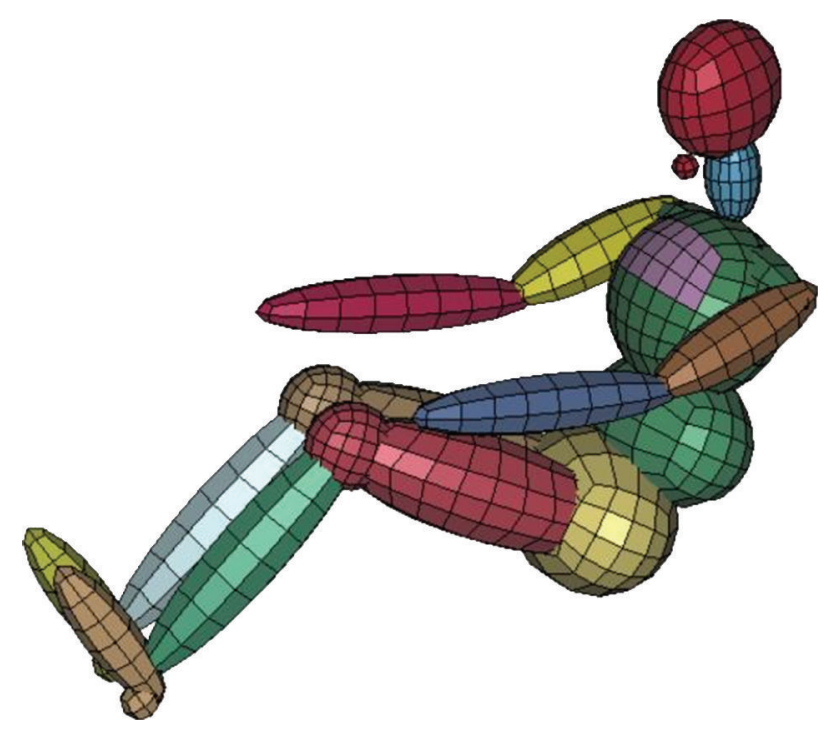

FIGURE 3: A rigid body dummy model representing a crew member in a blast event simulation.

2.3. Crew Model. Crash dummy models are usually included in tests and simulations to predict occupant responses under different crash loads; these responses will be used to guide the crashworthiness design. Various dummy models for vehicle crashworthiness design have been developed, from very complicated FE models with thousands of degrees of freedom (DOF) to much simpler rigid body models. Figure 3 shows the 50th percentile male GEBOD dummy model; the model is comprised of fifteen rigid bodies that represent the lower torso, middle torso, upper torso, neck, head, upper arms, forearms, and hands, and upper legs, lower legs, and feet of the dummy. The revolutions of the dummy are represented by spring elements with viscous damps. The dummy weighs $76 \mathrm{~kg}$, and the model has 1745 finite elements.

At present, specifically developed and validated human surrogate models suitable for assessing occupant response in a vehicle subject to mine strike are not available. Horst et al. [11] used the standard Hybrid III crash test dummy to study the lower leg injuries occurring in antitank mine strikes. Williams et al. [12] studied crew member responses in a light armored vehicle (LAV) subjected to a mine blast load by using the GEBOD rigid body dummy model incorporated in LSDYNA. Due to the computational efficiency of this dummy model, a total of six GEBOD dummies were put at different positions in the LAV for the simulation. In this work, the GEBOD dummy model shown in Figure 3 is employed for blast protection design because of its low computational cost and an acceptable error level. as [13]

The equation of occupant-seat model can be formulated

$$
\mathbf{M} \ddot{\mathbf{z}}+\mathbf{C} \dot{\mathbf{z}}+\mathbf{K z}=\mathbf{F}_{k}+\mathbf{F}_{c}
$$

where $\mathbf{z}=\left\{z_{s}, z_{1}, z_{2}, z_{3}, z_{4}\right\}^{T}$ is the displacement vector, $\mathbf{M}$, $\mathbf{K}$, and $\mathbf{C}$ are the mass matrix, the stiffness matrix, and the damping matrix, respectively and $\mathbf{F}_{k}$ and $\mathbf{F}_{c}$ are given as $\mathbf{F}_{k}=$ $\left\{k_{s} z_{0}, 0,0,0,0\right\}^{T}$ and $\mathbf{F}_{c}=\left\{c_{s} \dot{z}_{0}, 0,0,0,0\right\}^{T}$. Here, $k_{s}$ and $c_{s}$ are

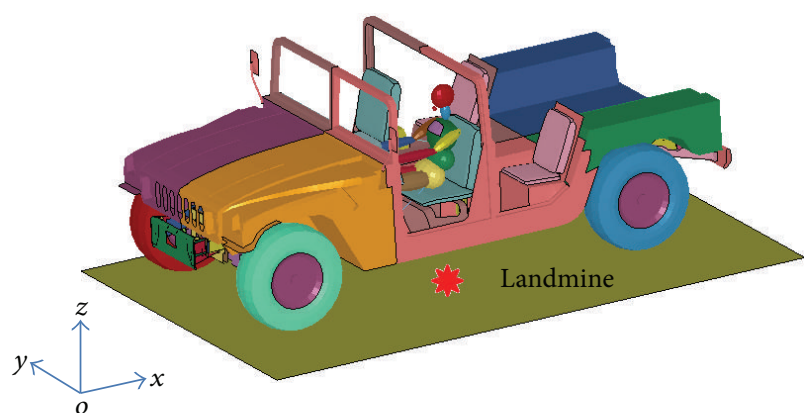

FIGURE 4: Simulation model of a crewed military vehicle under a landmine blast.

the stiffness and the damping coefficient of the suspension. $Z_{0}$ is the displacement of the suspension base and can be obtained from the integral of $\dot{z}_{0}$.

2.4. Blast Load Simulation Model. To simulate the blast load from an explosive device, such as a landmine, one of the empirical models for blast pressure prediction was utilized. This empirical model is based on the CONWEP air blast function developed by Kingery and Bulmash [14]. This model, which has been implemented as the $*$ LOAD_BLAST loading card in LS-DYNA, can predict the blast overpressure under certain conditions: the free air detonation of a spherical charge and the surface detonation of a hemispherical charge; the surface detonation approximates the conditions of a mine blast. The model takes into consideration the angle of incidence of the blast, $\theta$, the incident pressure, $p_{\text {in }}$, and the reflected pressure, $p_{\text {ref }}$. The predicted time-dependant blast overpressure is expressed as

$$
p(t)=p_{\mathrm{ref}} \cos ^{2} \theta+p_{\mathrm{in}}\left(1+\cos ^{2} \theta-2 \cos \theta\right),
$$

with $p_{\text {in }}$ and $p_{\text {ref }}$ given by

$$
\begin{aligned}
& p_{\text {in }}=p_{i 0}\left(1-\frac{t}{t_{0}}\right) e^{-b t / t_{0}}, \\
& p_{\text {ref }}=p_{r 0}\left(1-\frac{t}{t_{0}}\right) e^{-a t / t_{0}},
\end{aligned}
$$

where $p_{i 0}$ and $p_{r 0}$ are the peak incident overpressure and the peak reflected overpressure, respectively, $t_{0}$ is the positive phase duration time, and $a$ and $b$ are decay coefficients. By selecting appropriate values for $a$ and $b$, various decay characteristics can be indicated.

The solution methodology of wave propagation for the front and back facesheet of the composite sandwich structures is given by Hoo Fatt and Surabhi [15].

In this paper, the elastic wave speed in the foam $c_{e}$ is represented as

$$
c_{e}=\sqrt{\frac{E}{\rho_{f}}},
$$




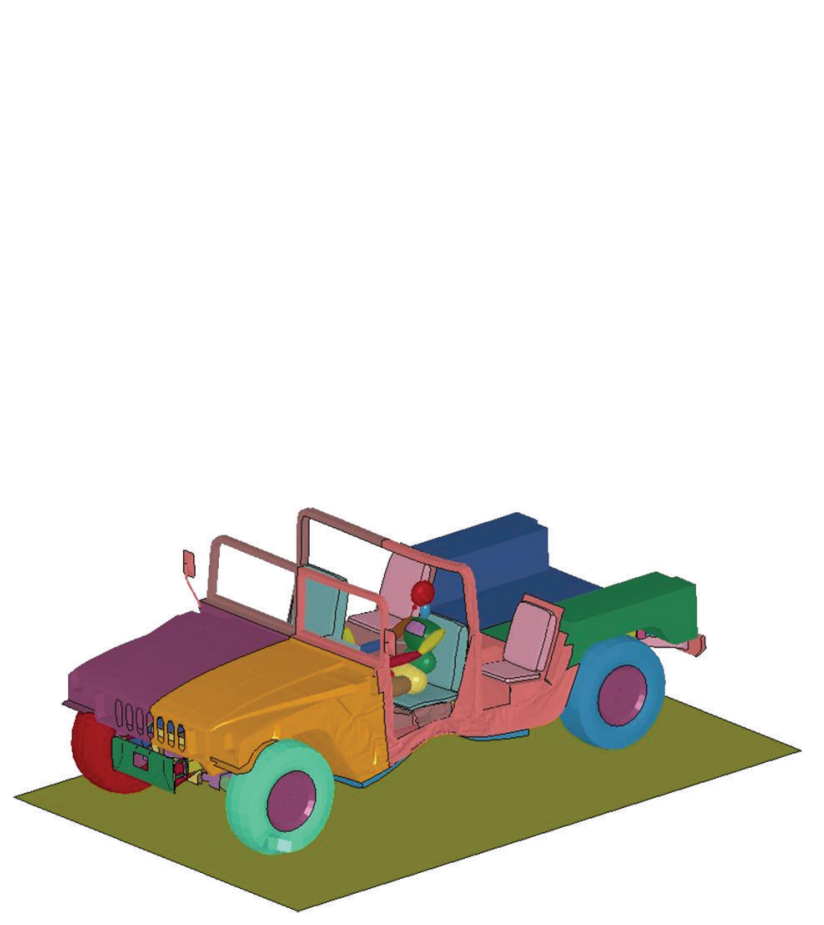

(a)
Contours of effective stress ( $\mathrm{v}-\mathrm{m})$

Max ipt. value

Min $=5252.22$, at elem. number 58529

Max $=1.68698 e+09$, at elem. number 55847

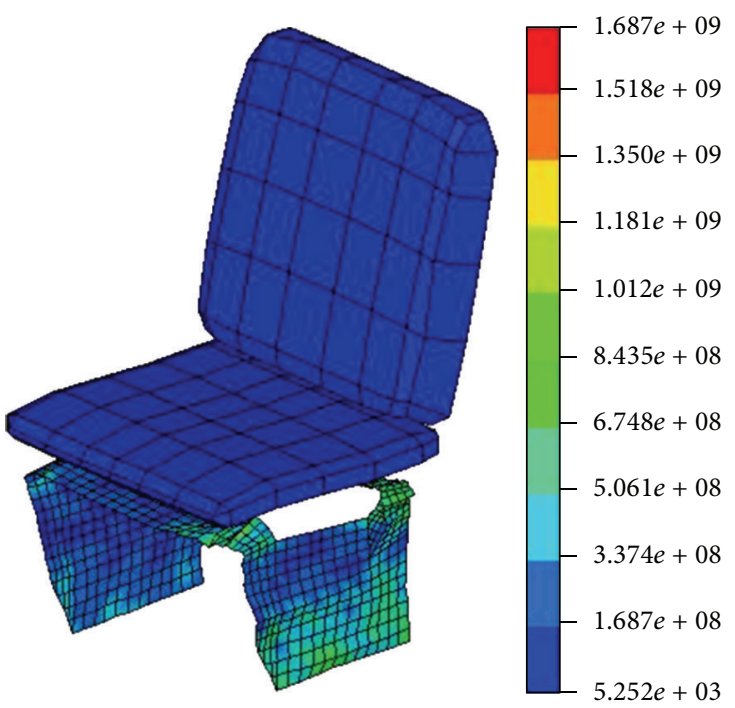

(b)

Vector of total velocity

Min $=0.0942307$, at node number 391

Max $=6.06069$, at node number 939

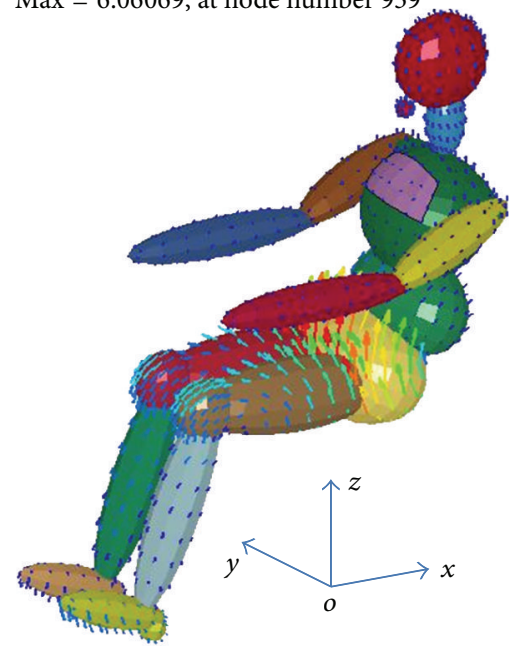

Fringe levels

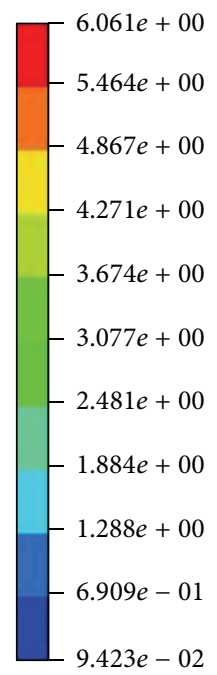

(c)

FIGURE 5: Simulations results. (a) Vehicle deformation. (b) Deformation and effective stress distribution of seat mounts. (c) Resultant velocity of crew.

while the plastic wave speed $c_{p}$ is

$$
c_{p}=\sqrt{\frac{E_{p}}{\rho_{f}}}
$$

where $E$ is the elastic modulus and $E_{p}$ is the elastic-plastic tangent modulus.
Hence, the resistive foam stress acting on the front facesheet (vehicle floor) about elastic wave propagation $\sigma_{f e}$ is

$$
\sigma_{f e}=\rho_{c} c_{e}\left(2 \dot{v}_{1 i}-\dot{v}_{1}\right)
$$

while the correponding stress about elastic-plastic wave propagation $\sigma_{f e p}$ is

$$
\sigma_{f e p}=\left(1-\frac{c_{p}}{c_{e}}\right) \sigma_{y}+\rho_{f} c_{p} \dot{v}_{1 \max }+\rho_{f} c_{e}\left(\dot{v}_{1 \max }-\dot{v}_{1}\right),
$$




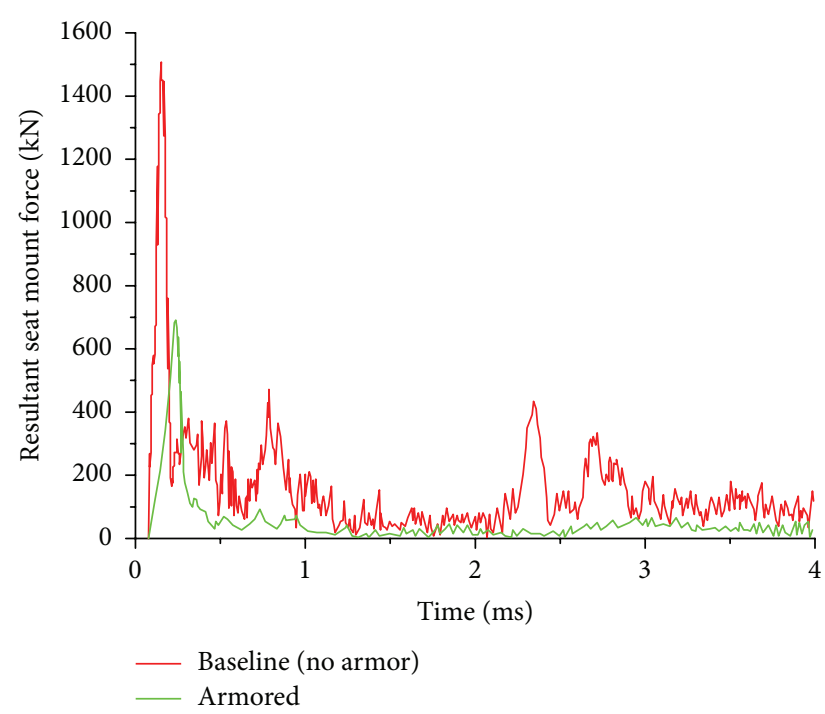

(a)

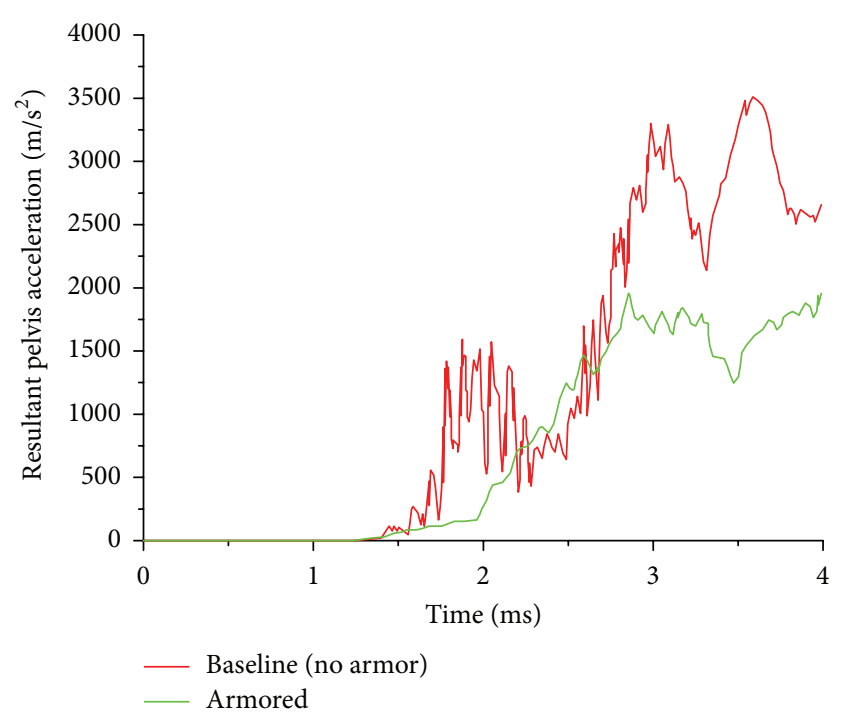

(b)

FIgURE 6: Comparison of blast-resistant capabilities of various designs with $2 \mathrm{~kg}$ TNT equivalent. (a) Seat mounts forces. (b) Crew pelvis acceleration.

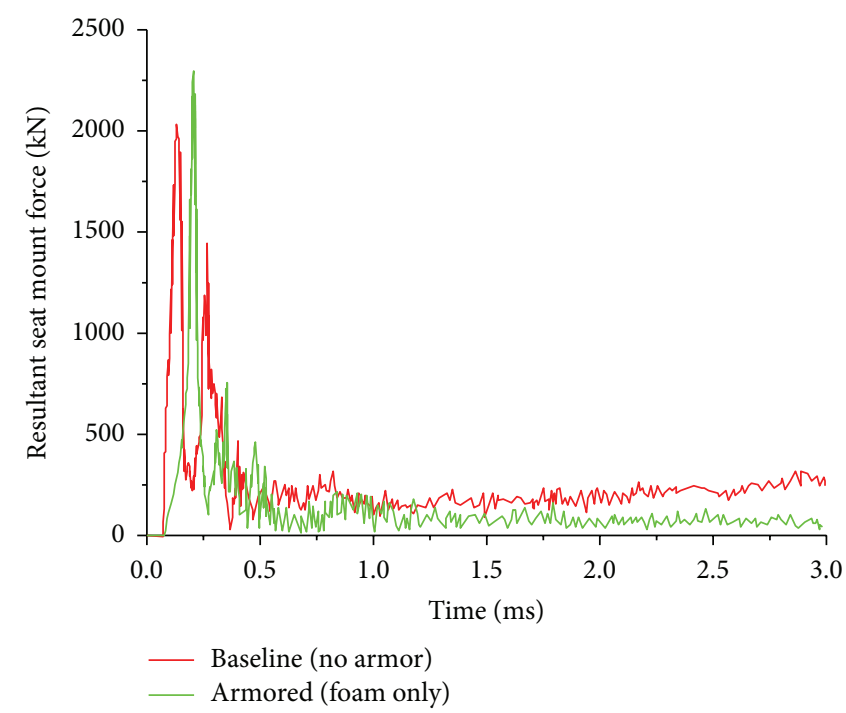

(a)

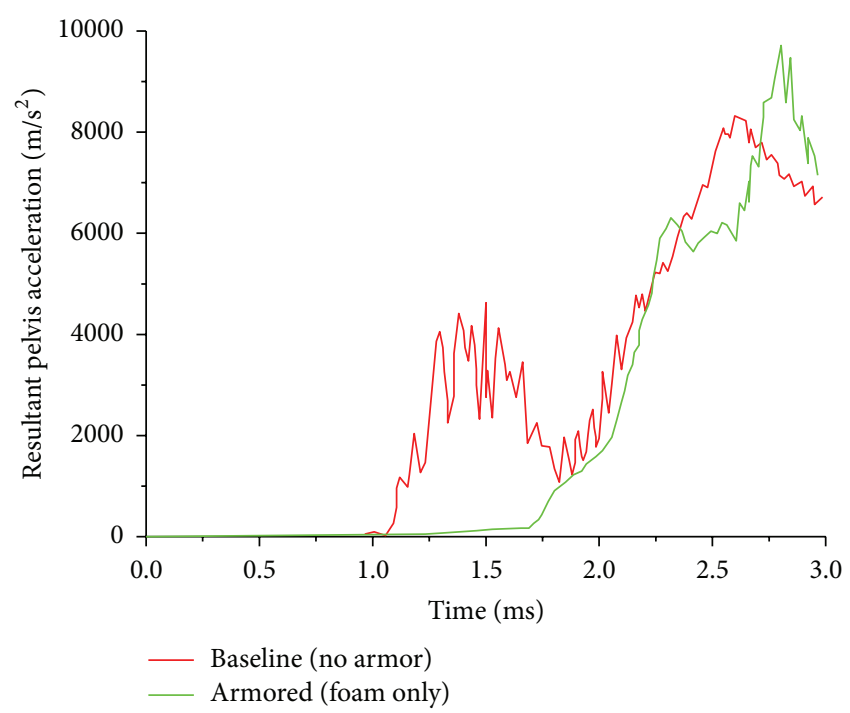

(b)

Figure 7: Comparison of blast-resistant capabilities of various designs with $4 \mathrm{~kg}$ TNT equivalent. (a) Seat mounts forces. (b) Crew pelvis acceleration.

where $\dot{v}_{1}$ is the particle velocity in the foam nearest to the vehicle floor, and it can be represented with the incident wave velocities $\dot{v}_{1 i}$ and the reflected wave velocities $\dot{v}_{1 r}$ as

$$
\dot{v}_{1}=\dot{v}_{1 i}+\dot{v}_{1 r}
$$

The resistive foam stress acting on the back facesheet (Al panel, as shown in Figure 2) about elastic wave propagation $\sigma_{b e}$ is given as

$$
\sigma_{b e}=\rho_{f} c_{e}\left(2 \dot{v}_{2 i}-\dot{v}_{2}\right)
$$

And the resistive foam stress acting on the back facesheet about elastic-plastic wave propagation $\sigma_{b e p}$ can be expressed as

$$
\begin{aligned}
\sigma_{b e p}= & \left(1-\frac{c_{p}}{c_{e}}\right) \sigma_{y}+\frac{c_{p}}{c_{e}} \sigma_{b e p i \max }-\left(\sigma_{b e p i \max }-\sigma_{b e p i}\right) \\
& +\rho_{f} c_{p} \dot{v}_{2 i \max }-\rho_{f} \mathcal{c}_{e}\left(\dot{v}_{2 i \max }-\dot{v}_{2 i}\right) \\
& -\rho_{f} c_{p} \dot{v}_{2 \max }+\rho_{f} \mathcal{c}_{e}\left(\dot{v}_{2 \max }-\dot{v}_{2}\right),
\end{aligned}
$$

where $\dot{v}_{2}$ and $\dot{v}_{2 i}$ are the particle and incident wave velocities in the foam nearest to the Al panel, $\dot{v}_{2 \max }$ and $\dot{v}_{2 i \max }$ are 
the maximum particle and incident wave velocities, and $\sigma_{b e p i}$ and $\sigma_{\text {bepi max }}$ are the incident and maximum incident stresses, respectively.

The model uses the following inputs to calculate the pressure: equivalent mass of TNT; coordinates of the point of explosion; and the delay time between when the LSDYNA solution starts and the instant of explosion. The model does not account for shadowing by the intervening objects or the effects of confinement. In this work, the CONWEP empirical model is adopted for blast load prediction by virtue of its computational efficiency and acceptable accuracy. The *LOAD_BLAST card in LS-DYNA is utilized to apply blast loads to the frontal panel of the structure, with the option ISURF set to 1 to represent a hemispherical charge situated on the surface.

\section{Simulation, Numerical Results, and Discussion}

Consider a general case when a landmine is denoted directly under the left seat mount, at a distance of $0.4 \mathrm{~m}$ below the vehicle floor (Figure 4). Two typical cases are simulated with explosive force equivalent to $2 \mathrm{~kg}$ and $4 \mathrm{~kg}$ of TNT, respectively. The purpose of these simulations is to predict the crew injuries under such accidents and to evaluate the blast-resistant capabilities of the vehicle underbody armor structure. The force transmitted to the seat mounts and the resultant acceleration of the crew member's pelvic under the blast load are the two major indices for the evaluation.

3.1. Blast Load Alleviation Effect. Figure 5 is the simulation results under the blast load with charge TNT equivalent of $2 \mathrm{~kg}$. The vehicle body structure deforms under the blast load pressure, as shown in Figure 5(a). The transmitted load causes the passenger seat to deform as illustrated in Figure 5(b). The crew body is accelerated due to the momentum transferred from the seat cushion as shown in Figure 5(c).

Compared with the baseline design without the underbody armor, the armored vehicle has a much reduced seat mount force, as shown in Figure 6(a), due to the blast energy absorption of the aluminum foam through plastic deformation. The crew's resultant pelvis acceleration is thus very much reduced in the armored design than in the original design, as shown in Figure 6(b).

According to the simulation results, the aluminum foam sandwich underbody armor is effective in protecting the crew member of a military vehicle in case the blast load is not above certain level.

3.2. Blast Load Enhancement Effect. In case the blast load intensity increases to a certain level (in the example problem, a TNT equivalent of $4 \mathrm{~kg}$ ) when the aluminum foam in the armor is fully compacted, the so-called force enhancement phenomenon will occur. Figure 6 shows that the resultant seat mount force (Figure $7(\mathrm{a})$ ) and the resultant pelvis acceleration (Figure 7(b)) are even higher in the armored vehicle than in the baseline design.

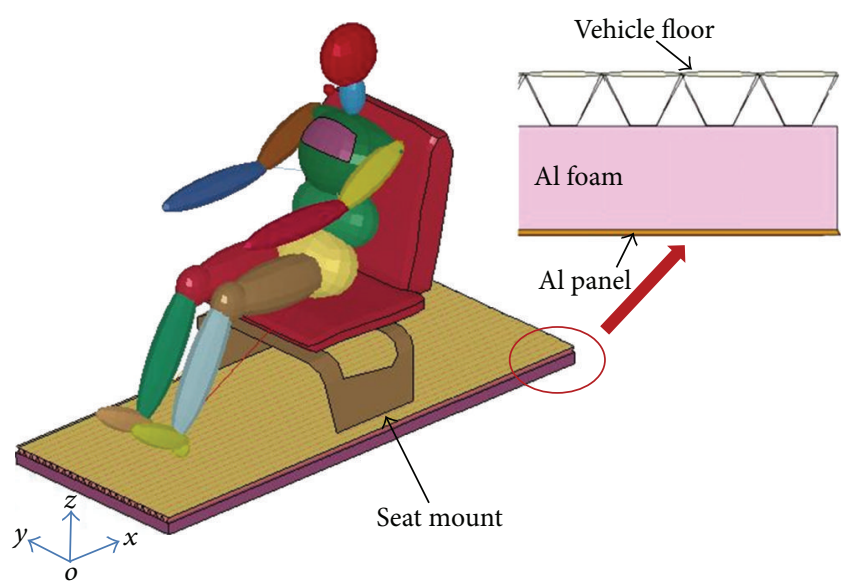

FIGURE 8: An innovative sandwich armor structure for blastresistant.

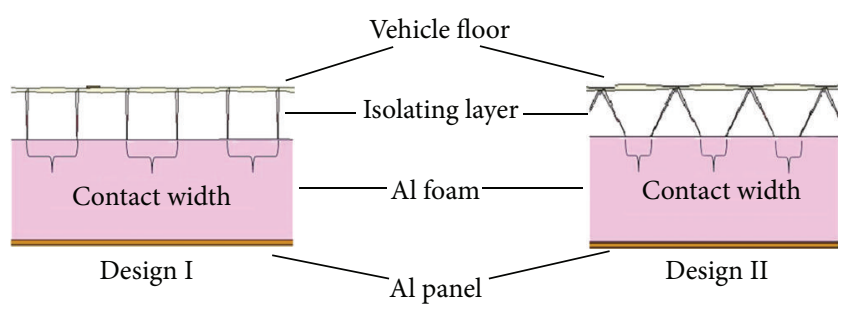

FIGURE 9: Design variations of sandwich armor structure with isolating layer.

\section{Isolating Structure Design to Eliminate Force Enhancement}

It is found that the mass density and stiffness mismatches between the metallic foam and the protected structure at the interface cause an "abrupt" momentum transfer, at the moment of foam densification. This is the physical cause of force enhancement.

In reality, a vehicle floor is designed for load bearing purposes; the mass density and stiffness of the floor material are usually not design variables for blast protection. To avoid possible force enhancement when the metal foam enables blast mitigation, alternative solutions are required. Introducing an isolating structure layer between the main structure and the aluminum foam results in an innovative sandwich armor structure as shown in Figure 8.

Figure 9 depicts the cross-sections of two different design configurations of the sandwich armor structure with isolating layer. The added weight of the isolating layer is the same for both Design I and Design II. Note that the isolating layer has less contact width (area) with the aluminum foam in Design II than in Design I.

The transmitted seat mount forces in different designs are compared in Figure 10; force enhancement occurs when the foam layer was fully compacted under the blast load; Design I eliminates the peak force transmitted to the seat mount, while Design II, which has less contact area between the isolating structure layer and the aluminum foam than 


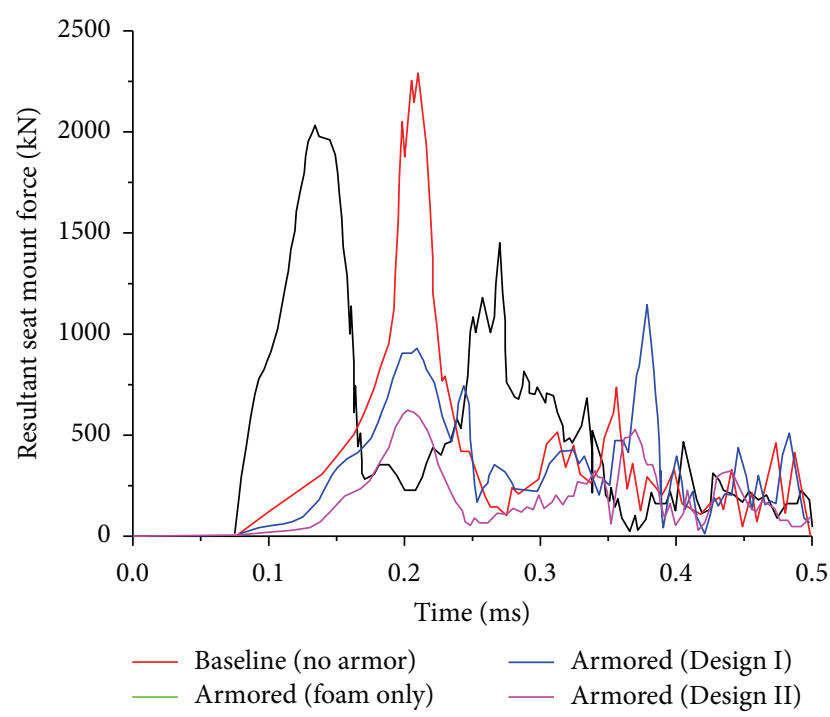

FIGURE 10: Comparison of seat mount forces in various designs.

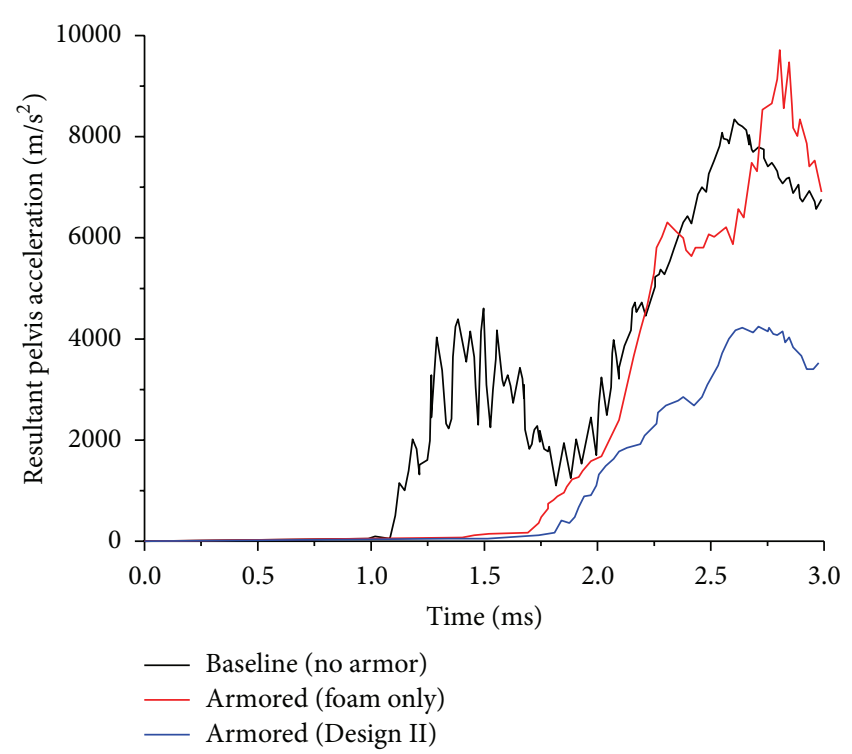

FIGURE 11: Innovative sandwich armor reduces crew injury.

Design I, reduces the force level even more. These results were further verified by examining the crew's pelvis accelerations as illustrated in Figure 11; with the introduction of the isolating layer in the sandwich armor structure and by decreasing the contact area between the isolating layer and the foam, the crew's pelvis acceleration caused by the force enhancement with the foam material under a blast load was greatly reduced. The crew's vulnerability to pelvic injury was effectively mitigated.

It is worth noting that the current work is a qualitative study of the proposed sandwich armor structure to show a good design strategy against force enhancement; a detailed study with design optimization is believed to give a more thorough and robust picture of the configurations of the blastresistant armor structure including metal foams.

\section{Conclusions}

A system-level finite element model is developed which includes the blast load, the military vehicle body, the sandwich armor, and the crew. Structure damages and crew injuries under a landmine explosion event are successfully predicted through numerical simulations using the developed model. The blast-resistant performances of the aluminum sandwich armor are evaluated based on the transmitted seat mount force and the resultant crew pelvic acceleration. It was found that a sandwich structure with only aluminum foam is effective in mitigating a moderate blast load. An isolating layer between the aluminum foam and the protected structure is effective in preventing force enhancement of foam material under severe blast loading. This innovative sandwich armor structure could be further designed for improved blast-resistant performances.

\section{Acknowledgments}

This work is funded by National Natural Science Foundation of China (nos. 50905024 and 51105053), Liaoning Provincial Natural Science Foundation of China (no. 20102026), the Research Fund for the Doctoral Program of Higher Education of China (nos. 20090041120032 and 20110041120022), and the Fundamental Research Funds for the Central Universities (DUT13Lk47).

\section{References}

[1] B. A. Gama, T. A. Bogetti, B. K. Fink et al., "Aluminum foam integral armor: a new dimension in armor design," Composite Structures, vol. 52, no. 3-4, pp. 381-395, 2001.

[2] R. Sriram, U. K. Vaidya, and J.-E. Kim, "Blast impact response of aluminum foam sandwich composites," Journal of Materials Science, vol. 41, no. 13, pp. 4023-4039, 2006.

[3] A. Schenker, I. Anteby, E. Nizri et al., "Foam-protected reinforced concrete structures under impact: experimental and numerical studies," Journal of Structural Engineering, vol. 131, no. 8, pp. 1233-1242, 2005.

[4] R. Monti, "Normal shock wave reflection on deformable solid walls," Meccanica, vol. 5, no. 4, pp. 285-296, 1970.

[5] H.-S. Kim, "New extruded multi-cell aluminum profile for maximum crash energy absorption and weight efficiency," ThinWalled Structures, vol. 40, no. 4, pp. 311-327, 2002.

[6] X. Zhang and G. D. Cheng, "A comparative study of energy absorption characteristics of foam-filled and multi-cell square columns," International Journal of Impact Engineering, vol. 34, no. 11, pp. 1739-1752, 2007.

[7] L. Aktay, B.-H. Kröplin, A. K. Toksoy, and M. Güden, "Finite element and coupled finite element/smooth particle hydrodynamics modeling of the quasi-static crushing of empty and foam-filled single, bitubular and constraint hexagonal- and square-packed aluminum tubes," Materials \& Design, vol. 29, no. 5, pp. 952-962, 2008.

[8] V. S. Deshpande and N. A. Fleck, "Isotropic constitutive models for metallic foams," Journal of the Mechanics and Physics of Solids, vol. 48, no. 6, pp. 1253-1283, 2000.

[9] A. G. Hanssen, Y. Girard, L. Olovsson, T. Berstad, and M. Langseth, "A numerical model for bird strike of aluminium 
foam-based sandwich panels," International Journal of Impact Engineering, vol. 32, no. 7, pp. 1127-1144, 2006.

[10] J. O. Hallquist, LS-DYNA Keyword User's Manual, Livermore Software Technology Corporation, Livermore, Calif, USA, 2007.

[11] M. V. D. Horst, C. Simms, R. V. Maasdam, and P. Leerdam, "Occupant lower leg injury assessment in landmine detonations under a vehicle," in Proceedings of the IUTAM Symposium on Biomechanics of Impact: from Fundamental Insights to Applications, Dublin, Ireland, 2005.

[12] K. Williams, S. Mclennan, R. Durocher, B. S. Jean, and J. Tremblay, "Validation of a loading model for simulating blast mine effects on armored vehicles," in Proceedings of the 7th International LS-DYNA Users Conference, 2002.

[13] Y. P. Dong and Z. H. Lu, "Analysis and evaluation of an anti-shock seat with a multi-stage non-linear suspension for a tactical vehicle under a blast load," Proceedings of the Institution of Mechanical Engineers D, vol. 226, pp. 1037-1048, 2012.

[14] C. N. Kingery and G. Bulmash, "Airblast parameters from TNT spherical air burst and hemispherical surface burst," Tech. Rep. ARBL-TR-02555, US Army BRL, Aberdeen Proving Ground, Md, USA, 1984.

[15] M. S. Hoo Fatt and H. Surabhi, "Blast resistance and energy absorption of foam-core cylindrical sandwich shells under external blast," Composite Structures, vol. 94, pp. 3174-3185, 2012. 

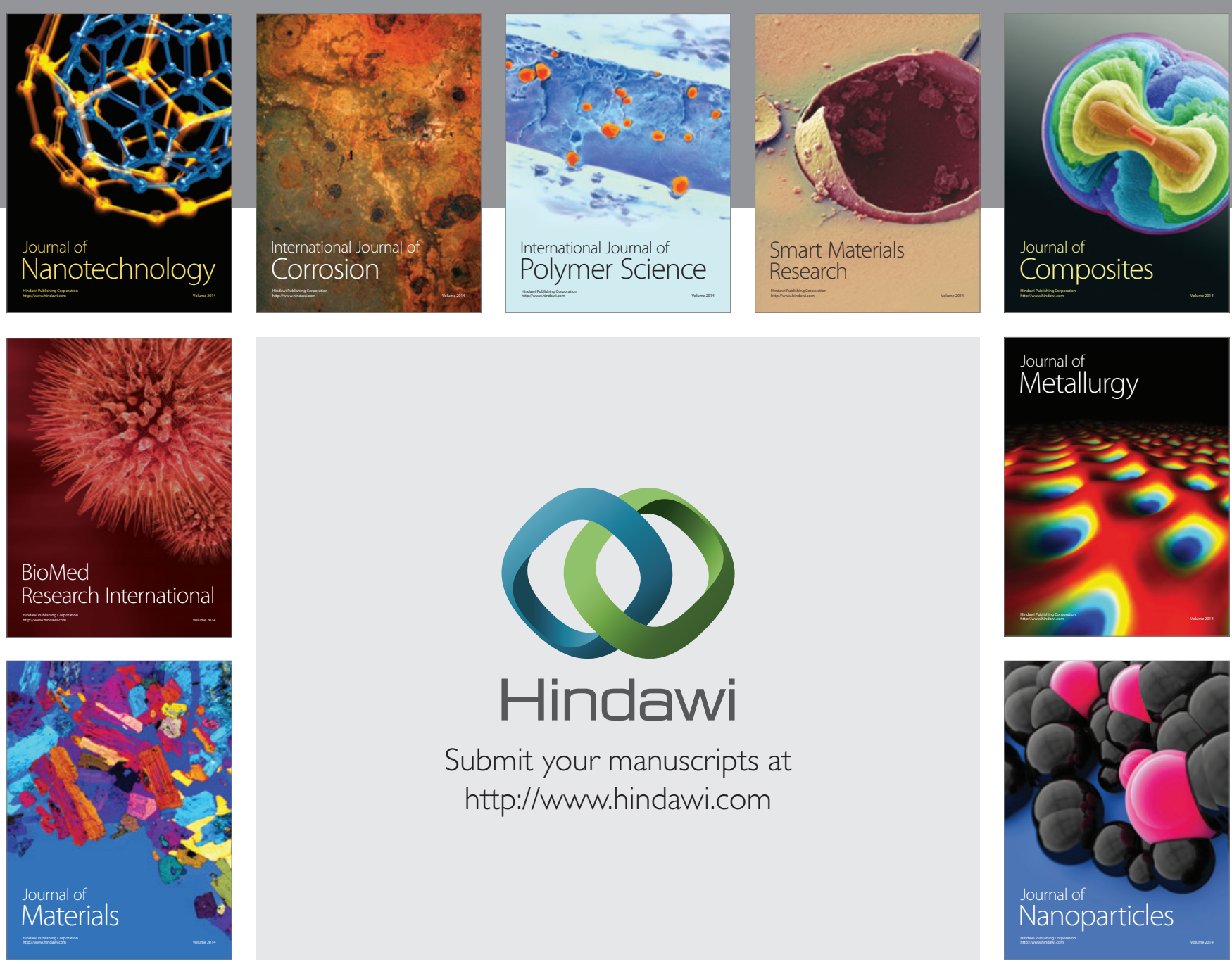

Submit your manuscripts at http://www.hindawi.com
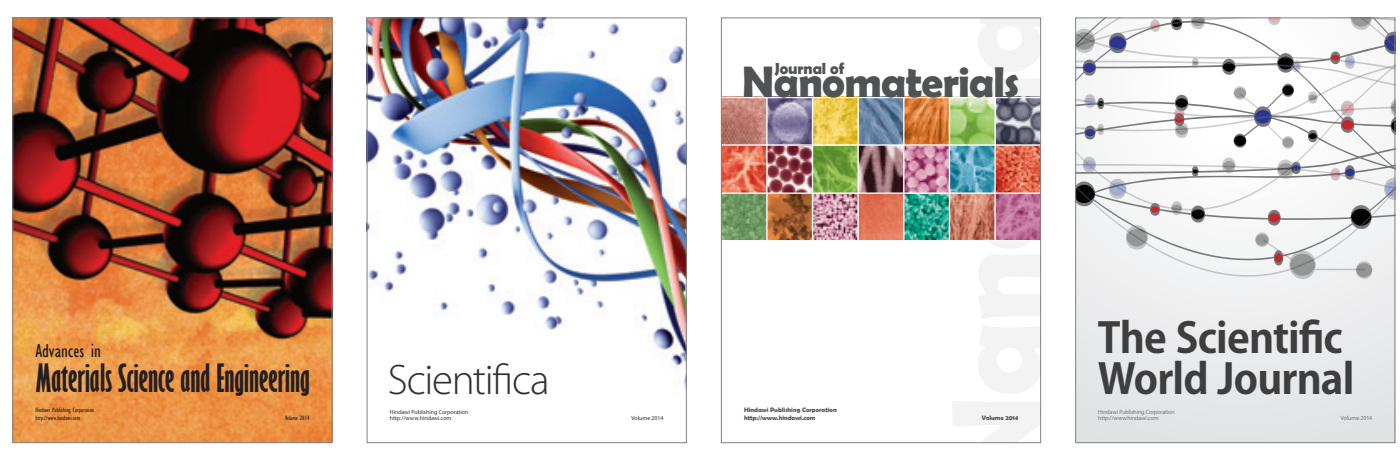

\section{The Scientific World Journal}
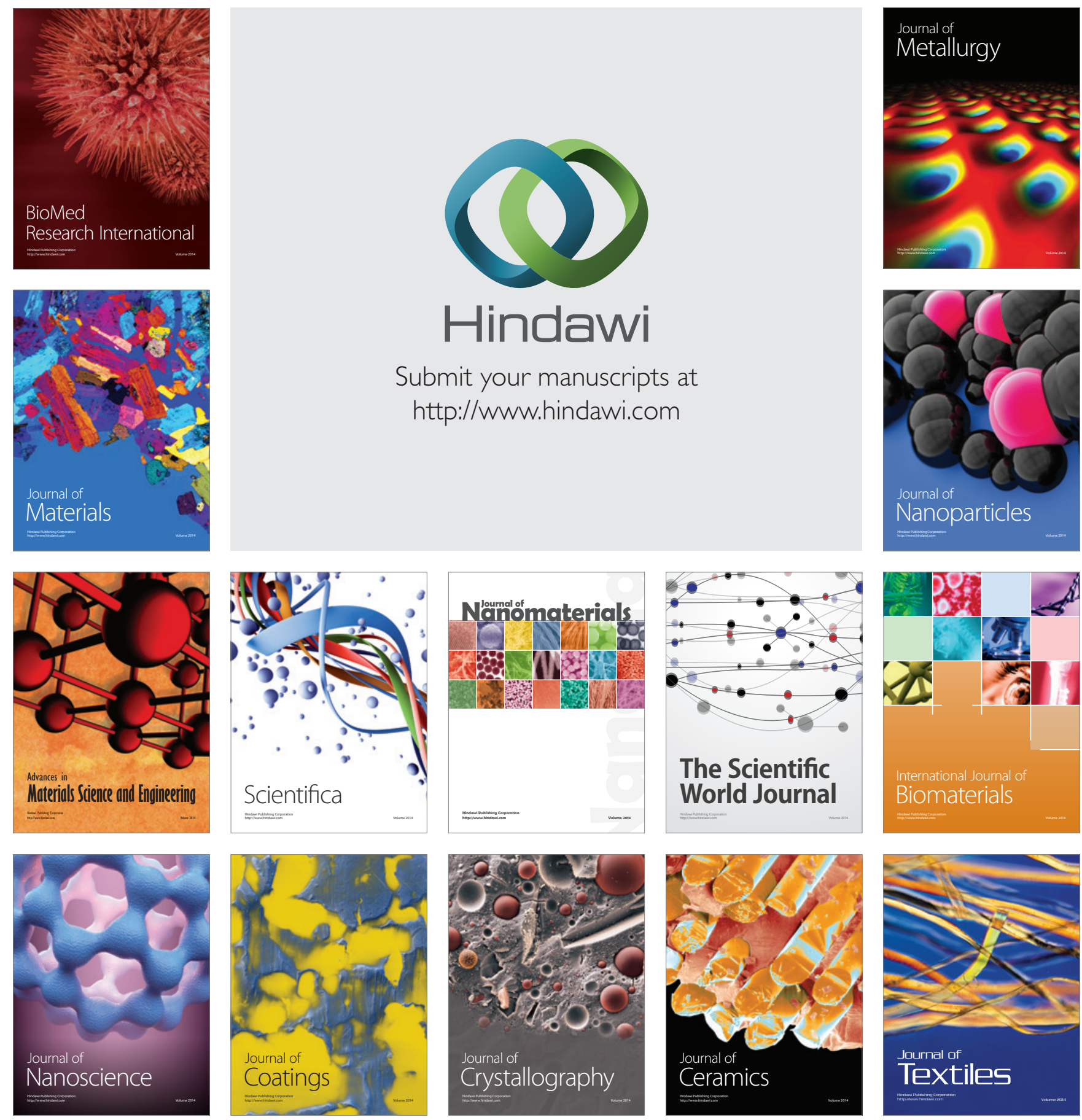